\title{
Mulemba
}

MULEMBA

Revista Angolana de Ciências Sociais

5 (9) | 2015

Olhares dispersos

\section{Riscos sociais, tecnologias e acidentes}

Social risks, technologies and accidents

João Areosa

\section{Q OpenEdition}

Journals

Edição electrónica

URL: http://journals.openedition.org/mulemba/348

DOI: 10.4000/mulemba.348

ISSN: 2520-0305

\section{Editora}

Edições Pedago

Edição impressa

Data de publição: 1 maio 2015

Paginação: 19-53

ISSN: 2182-6471

\section{Refêrencia eletrónica}

João Areosa, «Riscos sociais, tecnologias e acidentes», Mulemba [Online], 5 (9)| 2015, posto online no dia 28 novembro 2016, consultado o 26 janeiro 2021. URL: http://journals.openedition.org/mulemba/ 348 ; DOI: https://doi.org/10.4000/mulemba.348

Este documento foi criado de forma automática no dia 26 janeiro 2021.

Tous droits réservés 


\section{Riscos sociais, tecnologias e acidentes}

Social risks, technologies and accidents

João Areosa

\section{NOTA DO EDITOR}

Recepção do manuscrito: 02/02/2015

Aceite para publicação: 05/04/2015

\section{Introdução}

Existem alguns sinais nas sociedades contemporâneas que nos indicam um aumento da preocupação em torno de alguns riscos, nomeadamente sociais e tecnológicos. Esta temática tem vindo a ganhar alguma importância, particularmente quando os riscos dão origem a cenários de tensão social (sobretudo quando estamos perante níveis elevados de desemprego, precariedade, xenofobia ou desigualdades sociais), a desastres naturais, a acidentes industriais graves ou quando não existe consenso sobre os efeitos que eles (riscos) podem produzir. A problematização da aceitabilidade social dos riscos e os múltiplos factores que contribuem para formulação das percepções de riscos (AREOSA 2011; 2012a; 2014) são dois pequenos exemplos que demonstram a actual complexidade existente no debate destes assuntos. Contudo, quando falamos sobre o risco verificamos que estamos sempre perante cenários de incerteza, onde os resultados nunca podem estar garantidos à partida (caso contrário não seriam situações de risco). O conceito de «sociedade de risco», protagonizado por Beck (1992), traduz precisamente a incerteza quanto a alguns resultados futuros. Neste trabalho, depois de debatermos a noção de risco (incluindo algumas das suas implicações sociais), passamos para a discussão dos riscos tecnológicos na contemporaneidade, sabendo que este é um dos 
temas amplamente abordado nas perspectivas de Ulrich Beck, Anthony Giddens e Charles Perrow.

\section{Risco: reflexões em torno de uma definição conceptual}

2 A origem da palavra risco, referida na literatura, está longe de ser consensual e não foi definida com precisão (MELA et al., 2001: 159). Para Spink (2001), o termo risco teve a sua génese na pré-modernidade, concretamente no período de transição entre as sociedades feudais e a emergência dos Estados-nação. A autora refere ter encontrado o primeiro registo da palavra risco num documento castelhano do século XIV. Segundo Luhmann (1993: 9) a etimologia do risco é desconhecida, embora se suspeite que a sua origem possa vir do árabe. Este autor aponta também para que a expressão risco tenha surgido na transição da idade média para a era moderna. Na mesma linha de pensamento Bernstein (1996) refere que o conceito de risco parece ter surgido nas civilizações hindo-arábicas. Já na óptica de Giddens (2000) é indicado que a noção de risco pode ter aparecido na península ibérica, no decorrer dos séculos XVI ou XVII, onde se tentava caracterizar a navegação por mares desconhecidos, ainda sem descrição nas cartas marítimas da época. Na etimologia do risco estava incluída a dimensão de espaço, particularmente, a noção de espaço físico ou território desconhecido. Posteriormente o conceito de risco foi utilizado pelos sistemas bancários para projectar investimentos; a partir deste momento a noção de risco passou a incluir a dimensão de tempo, fundamental para efectuar os cálculos prováveis desses mesmos investimentos.

3 Tal como se pode verificar, as posições sobre a etimologia do risco são muito diversificadas. Num dos seus trabalhos mais recentes Neto (2013) aprofunda o debate sobre esta questão de forma bastante consistente. Da pesquisa (não exaustiva) que realizámos, a primeira referência à noção de risco que conseguimos detectar foi redigida no século XIII (4 de Abril de 1248), num documento italiano, de Génova, relacionado com aspectos da navegação (cf. REBELO 2005). Os perigos associados à navegação desta época (quer em termos de perdas de bens, quer de pessoas) seriam, seguramente, bem conhecidos, logo é bastante provável que a palavra risco tenha surgido com estreita ligação às actividades marítimas. Bernstein (1996) corrobora que a origem do termo risco ocorreu acerca de sete ou oito séculos atrás, derivada da expressão italiana risicare, a qual significa ousar ou desafiar. ${ }^{1}$ Deste modo, seria expectável que o risco não se configurasse tanto como um destino pré-determinado, mas antes uma opção passível de escolha. Contudo, outros autores não partilham esta opinião, dado que - sustentam eles - nos primórdios do termo risco este não aparece associado a escolhas humanas. Dentro desta perspectiva o risco era visto como uma força maior, um acto divino ou um perigo objectivo que não podia ser imputado ao homem. Nesta visão conceptual estavam excluídas, quer a responsabilidade, quer as falhas humanas. O risco era percebido como um evento natural ${ }^{2}$ (tempestades, inundações ou tornados) ou como uma vontade divina e não como algo passível de ser feito pelo homem. Esta noção também apontava para que alguns acontecimentos adversos para a humanidade pudessem ser vistos como castigos dos deuses, ${ }^{3}$ provocados pela sua ira contra a humanidade (LUPTON 2003). 
O sentido original dado ao termo risco remete-o para alguma neutralidade. Isto é, o risco em si mesmo é uma entidade neutra (EWALD 1991) e abstracta que necessita de estar ligada a uma situação concreta para ganhar sentido. Porém, actualmente, devido à multiplicidade de situações e conotações que a noção de risco incorpora, parece difícil concebê-lo como uma entidade neutra.

«Do uso original aos múltiplos usos sociais que têm sido feitos do termo "risco", em diversas arenas de experiência social, surge uma realidade despojada de neutralidade e construída com diversas tonalidades, irreconhecíveis na matriz da sua concepção original. Associa-se ao risco a ideia da sua configuração multidimensional e a ideia de heterogeneidade das suas significações» (CARAPINHEIRO 2001: 198).

5 Por norma, o conceito de risco está associado a potenciais factores ou acontecimentos negativos, indesejados e, por vezes, inesperados, fruto da condição de forte incerteza da vida quotidiana. Alguns riscos são globais, por isso as formas como influenciam o rumo das sociedades são um aspecto que deve ser considerado em diversas vertentes, nomeadamente, política, social e económica. Parece que nos dias de hoje a noção de risco está a assumir uma importância central nas sociedades; dentro desta lógica defendemos que o debate em torno do conceito de risco deve ser amplamente promovido e desmistificado ao nível científico e clarificado perante a opinião pública. ${ }^{4}$ Em certos casos sabemos que os riscos podem originar medo ou pânico. Contudo, o risco nem sempre deve estar associado a uma abordagem negativa e pessimista, dado que ele pode ser analisado e avaliado numa vertente positiva. Este aspecto é, por exemplo, demonstrado através da citação seguinte: «Sendo certo que o risco comporta, em geral, um lado positivo - a probabilidade de alcançar as vantagens esperadas - e um lado negativo - a probabilidade de ter de suportar as desvantagens esperadas» (HESPANHA e CARAPINHEIRO 2002: 14). Para além disso, também nos parece relevante destacar que a distribuição dos riscos é normalmente assimétrica entre os diversos grupos sociais. Apesar disto, o risco tornou-se numa inevitabilidade suportada quotidianamente pelas massas (SENNETT 2001: 125) ou, como preconiza Dean (1999: 146), o risco pode ser visto como um continuum e neste sentido nunca desaparece completamente. Na verdade isto significa que estamos perenemente em risco.

6 Para Beck (1992: 46) o risco não é uma invenção dos tempos modernos, embora tenha modificado significativamente o seu sentido durante este período. Todavia, devido à sua ancestral ligação com a história da humanidade algumas situações de risco acabam por ser bem toleradas em determinadas actividades da vida social. Na perspectiva de Beck a modernidade transformou-se num período de retorno à incerteza ou como afirma Bauman (1991) no fim do inequívoco (unambiguity). Paralelamente, alguns autores defendem que deveria ser a incerteza (e não o risco) o centro da análise na modernidade (MARTINS 1998). É também por isso que o risco deveria ser visto como um caminho específico para tentar transformar as incertezas futuras em algo passível de ser gerido. Porém, nunca se deve esquecer as inúmeras limitações e indeterminações que as previsões do futuro nos podem reservar (TALEB 2008).

7 Verifica-se que é relativamente frequente tentarmos racionalizar os riscos que julgamos correr; todavia, em muitas situações, isso não passa de mera ilusão, pois os riscos que acabam por nos afectar são, por vezes, muito diferentes daqueles que nós idealizámos.

«O que há de irónico no risco é que a racionalidade - ou seja: a experiência do passado - estimula a previsão de um tipo errado de risco, daquele que nós supomos 
poder calcular e dominar, mas o desastre provém daquilo que nós não conhecemos nem podemos calcular. As amargas variações desta ironia do risco são virtualmente infinitas: a doença das vacas loucas, os ataques do 11 de Setembro, as crises financeiras globais, o vírus da gripe dos suínos e a mais recente, se bem que não a última: as nuvens de cinza vulcânica que interrompem o tráfego aéreo na Europa e no mundo» (BECK 2013: 31).

Kaplan e Garrick (1981) defendem que quando perguntamos «o que é o risco?» estamos, de facto, a fazer três perguntas: $O$ que pode acontecer? Qual a probabilidade de isso acontecer? E, se isso acontecer, quais serão as consequências? A primeira questão está relacionada com o cenário de perigo. A segunda interroga-se sobre a probabilidade ou possibilidade de determinado evento ocorrer. E finalmente, a terceira pergunta, está relacionada com as consequências indesejadas na projecção de um cenário específico.

9 Covello e Merkhofer (1993) caracterizam o risco como uma situação onde dois ou mais resultados são possíveis de acontecer, desconhecendo-se, no entanto, qual será o resultado particular que irá ocorrer. Assim, o conceito de risco remete-nos para probabilidades ou possibilidades sobre a ocorrência de eventos futuros, decorrente das diversas dinâmicas do mundo social. Apesar da abordagem ao risco estar essencialmente direccionada para possíveis situações futuras, isto não significa que deixemos de incorporar a nossa experiência passada na avaliação de eventuais acontecimentos vindouros, visto que isto nos permite obter alguns parâmetros comparativos para «saber» como lidar com situações de risco semelhantes. Para tentar combater alguns factores de incerteza relativos ao futuro utilizamos quase sempre o nosso capital de conhecimentos como guia para as nossas acções no presente. Segundo Giddens (1994: 114) correríamos um maior número de riscos nas nossas vidas quotidianas, caso a nossa socialização não contemplasse diversos mecanismos protectores e de vigilância para lidarmos com os riscos; isto é definido pelo autor como normalidade conquistada. Assim, a nossa aprendizagem geral inclui também a aprendizagem das situações de risco. As diversas capacidades que vamos ganhando e construindo ao longo das nossas vidas, para lidar com as múltiplas formas de risco, formam aquilo que Giddens designa como casulo protector.

10 A essência do risco não é aquilo que está a acontecer, mas antes aquilo que pode vir a acontecer (ADAM e VAN LOON 2000). Segundo Douglas e Wildavsky (1982) o risco é socialmente construído, e, por vezes, afigura-se como algo incontrolável, visto que nós nem sempre conseguimos saber se aquilo que estamos a fazer é suficientemente seguro para prevenir a ocorrência de acidentes ou de efeitos indesejados. Para além disso, ninguém consegue conhecer mais do que uma pequena fracção dos perigos e dos riscos que se encontram em seu redor, dado que a visão dos actores sociais sobre os riscos aos quais estão sujeitos é sempre parcial ou incompleta. Todavia, os riscos estão sempre connosco! De certo modo, isto significa que o risco é omnipresente e por vezes transforma-se numa espécie de «fantasma» que paira sobre as nossas mentes, sendo susceptível de nos causar medo. Mas isso não são propriamente boas notícias, pois o medo pode ser paralisante; e também parece que temos cada vez mais medo, apesar de sermos as pessoas mais saudáveis, mais ricas e mais longevas de toda a história da humanidade (GARDNER 2008).

11 A essência do risco remete-nos para cenários hipotéticos ou condicionais, sabendo que está sempre presente uma certa dose de incerteza quanto aos resultados vindouros. Se o futuro fosse algo pré-determinado e independente das ocorrências do presente (actividades humanas ou forças da natureza) o termo risco não faria sentido (RENN 
1992). Apesar da pluralidade conceptual do risco ${ }^{5}$ parece existir um elemento transversal a todas as suas definições: a distinção entre possibilidade e realidade (RENN 1992), ou seja, aquilo que é possível acontecer pode ou não transformar-se em realidade. Por este motivo, a incerteza é um dos pressupostos mais importantes do risco. Em qualquer dos casos o risco será sempre uma espécie de antecâmara para acontecimentos futuros. Quando afirmamos que alguém ou algo está em risco, isto significa o evento ainda não ocorreu. É neste sentido que, segundo Adams (2005), o risco é, em parte, fruto da nossa mente, dado que traduz essencialmente uma projecção incerta de «acontecimentos» que podem (ou não) vir a ocorrer. Numa linha de pensamento similar Slovic (2001: 23) preconizou que «os perigos são reais, enquanto os riscos são construções sociais».

12 No universo social quotidiano as novas formas de risco aumentaram exponencialmente (GIDDENS 2000), diríamos mesmo que o risco se tornou hegemónico. Isto é, nem sempre o risco é uma situação passível de escolha para a maioria da população, em termos de exposição voluntária, restando-lhe, por vezes, uma coabitação imposta nos seus complexos domínios. Nas actuais sociedades «mais desenvolvidas» parece fazer todo o sentido efectuar a distinção entre os riscos atribuídos a causas de origem natural e os riscos produzidos pelo próprio homem. ${ }^{6}$ Por riscos naturais entendemos todos os acontecimentos provocados pelo meio natural e sobre os quais o homem não contribuiu directamente para a sua ocorrência. Incluimos neste tipo de riscos, a título de exemplo, as erupções vulcânicas, os sismos, os ciclones, os incêndios (onde não exista participação humana), os raios resultantes das diferentes cargas eléctricas das massas de ar, etc. Por riscos produzidos pelo próprio homem entendemos todo o tipo de situações onde sejam utilizados equipamentos, produtos ou substâncias sintetizadas pelas múltiplas actividades humanas, nomeadamente a tecnologia das centrais nucleares, a utilização de gases tóxicos, de produtos químicos e de substâncias radioactivas ou a poluição do meio ambiente por acção do homem.

Os perigos e consequentes riscos produzidos nas sociedades contemporâneas assumiram proporções nunca vistas em toda a história da humanidade (BECK 1992). Aquilo que pode ser visto hoje como um comportamento seguro transforma-se amanhã num comportamento de risco, à luz das novas reivindicações do conhecimento científico ou dos próprios saberes leigos. Para Giddens (1998: 28) o conhecimento na modernidade reflexiva não tem o mesmo significado do passado, isto é, já não significa ter a certeza. E esta novidade é válida tanto para as ciências sociais, como para as ciências naturais. Na modernidade o conceito de risco está associado à confiança e veio substituir a noção de fortuna, por alteração de determinadas percepções (GIDDENS 1998: 24).

14 A confiança opera essencialmente em ambientes de risco e ela só é necessária quando existe ignorância (GIDDENS 1998). No entanto, a ignorância pode também provocar no público leigo algum cepticismo, precaução ou ansiedade. As garantias simbólicas dos sistemas abstractos dependem em larga medida da confiança que lhes é atribuída, mas é através deles que se pretende criar largas áreas de segurança para a vida do cidadão comum contemporâneo (GIDDENS 1994: 119). Todavia, nem sempre essa meta é possível de atingir. Para Giddens (1998) ninguém consegue realizar escolhas completamente fora dos sistemas abstractos, ou seja, sem envolver as instituições modernas; embora, os sistemas periciais abstractos sejam, simultaneamente, potenciais geradores de novas situações de risco, as quais nem sempre estamos aptos para enfrentar, nomeadamente 
os altos riscos do mundo moderno (GIDDENS 1994: 121). Alguns dos altos riscos da modernidade são virtualmente impossíveis de perspectivar com rigor, visto que ninguém pode afirmar com «absoluta certeza» se determinada situação pode (ou não) acontecer e se acontecer, quais serão os seus efeitos. As eventuais consequências negativas do aquecimento global da terra encontram-se dentro deste padrão de altos riscos (GIDDENS 1994: 122).

Deste modo, determinados riscos globais, tais como: guerras nucleares, catástrofes ecológicas ou o colapso da economia global, implicam, segundo a designação de Beck (1992), o «fim dos outros», devido à ruptura de fronteiras entre aqueles que são afectados e aqueles que não são. Perante este tipo de riscos todos somos vulneráveis aos seus possíveis efeitos. Na realidade, alguns dos riscos actuais parecem assumir uma espécie de efeito boomerang, isto é, metaforicamente, quem «lança» o risco arrisca-se também a ser uma das suas potenciais vítimas. Na sequência do pensamento sobre os riscos globais, Giddens coloca a tónica em quatro grandes estruturas de risco na modernidade, ou seja, aquilo que ele define como altos riscos da modernidade. Este conceito é entendido pelo autor como as situações susceptíveis de afectar um elevado número de indivíduos, das quais podem resultar qualquer ameaça às suas próprias vidas (GIDDENS 1994: 100). $\mathrm{Na}$ figura 1, Giddens apresenta quatro pontos que podem exemplificar os altos riscos $d a$ modernidade. Estes novos riscos geram potenciais instabilidades, designadas a partir da noção de «clima de risco». O clima de risco vivenciado nas sociedades contemporâneas torna-se inquietante para todos e não é passível de fuga para ninguém.

Figura 1 - Altos riscos da modernidade

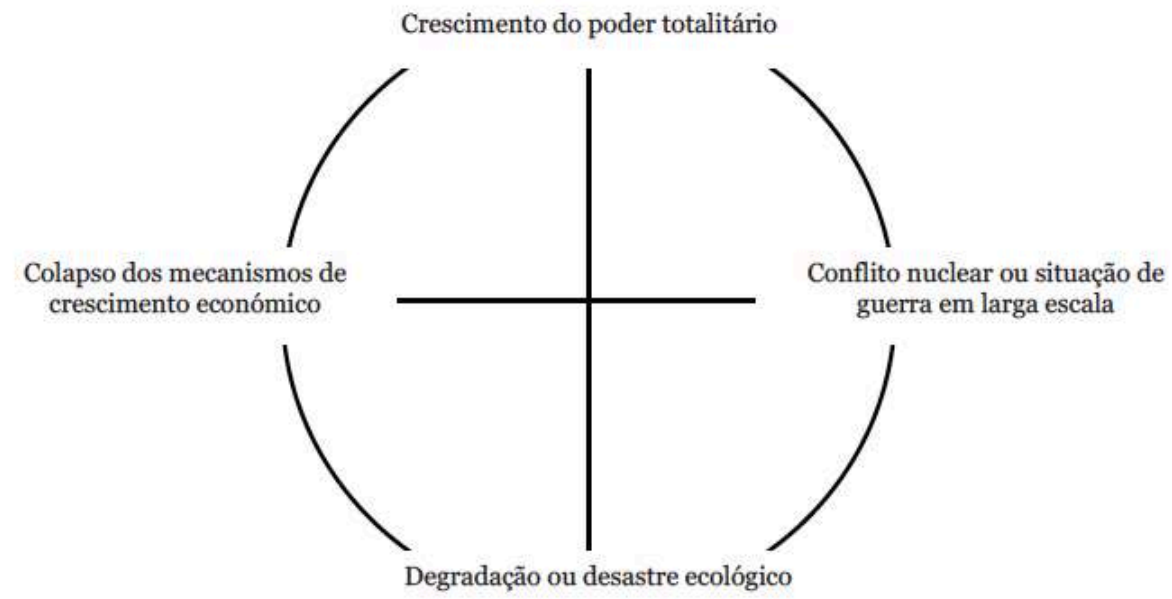

Fonte: ADAPTADO DE GIDDENS (1998: 120).

O risco não é apenas um problema da aç̧ão individual, embora recaia também sobre o indivíduo. Na perspectiva de Giddens (1998: 25) existem inúmeros «ambientes de risco», logo, esta condição revela o seu carácter colectivo. A vida actual obriga-nos a viver num mundo de risco. Isto significa que existe sempre a possibilidade de algo correr mal, mas, o pior de tudo é que essa possibilidade não pode ser eliminada (GIDDENS 1998). Para definir esta condição o autor avança com o conceito de perfil de risco. Esta noção compreende o conjunto particular de ameaças (ou de perigos) que caracterizam a vida social moderna. $\mathrm{O}$ sociólogo britânico esboça, através de sete grandes itens, aquilo que 
pretende traçar como os pontos mais significativos do perfil de risco da modernidade, particularmente as potenciais catástrofes globais, as quais representam um horizonte de riscos tendencialmente assustadores para toda a humanidade. Os quatro primeiros pontos referem-se à distribuição objectiva do risco e/ou intensidade do risco, entendidos normalmente como elementos ameaçadores do mundo moderno, enquanto os três últimos pontos abordam as formas de alteração da percepção dos riscos observados.

«1 - Globalização do risco no sentido da intensidade: por exemplo, a guerra nuclear pode ameaçar a sobrevivência da humanidade; 2 - Globalização do risco no sentido do crescente número de acontecimentos contingentes que afectam todas as pessoas ou, pelo menos, um elevado número de pessoas no planeta: por exemplo, mudanças na divisão global do trabalho; 3 - Riscos decorrentes do ambiente criado, ou natureza socializada: a infusão de conhecimento humano no ambiente material; $4-$ Desenvolvimento de ambientes de risco institucionalizado que afectam as oportunidades de vida de milhões de pessoas: por exemplo, os mercados de investimentos; 5 - Consciência do risco enquanto risco: as «falhas de conhecimento» sobre os riscos não podem ser convertidas em «certezas» através do conhecimento religioso ou mágico; 6 - Consciência bem difundida do risco: muitos dos perigos que enfrentamos colectivamente são conhecidos por vastos públicos; 7 - Consciência das limitações da pericialidade: nenhum sistema pericial o pode ser totalmente em termos das consequências da adopção de princípios de pericialiadade» (GIDDENS 1998: 87 e 88).

17 Nas nossas vidas existem sempre alguns perigos e riscos insuspeitos. Determinadas inovações ou invenções foram criadas com o objectivo de nos proteger, para tornar as coisas mais seguras, mas, por vezes, acabam por nos trazer efeitos adversos, transformando-se em novos perigos; Douglas e Wildavsky (1982) dão como exemplo os casos do RX e do amianto. À medida que o nosso conhecimento vai aumentando a relação custo/benefício de certos riscos pode alterar-se. Um risco pode ser hoje considerado aceitável, para amanhã ser completamente repudiado na sociedade. Devemos ter presente que qualquer coisa pode provocar riscos (DOUGLAS e WILDAVSKY 1982: 19). É pertinente não esquecer que as pessoas elaboram as suas próprias apreciações sobre os riscos, e é em grande medida a partir daqui que resultam as suas decisões sobre aceitarem ou evitarem esses mesmos riscos. Eiser (2004) elaborou um fluxograma simplificado, onde desenvolve alguns factores que influenciam os julgamentos do público perante cenários de risco ou ameaça. Nesta representação (figura 2), além das dimensões sociais, encontra-se também incorporado o portfolio de experiências individuais de cada agente social. 
Figura 2 - Fluxograma da representação do processo de julgamentos públicos do risco

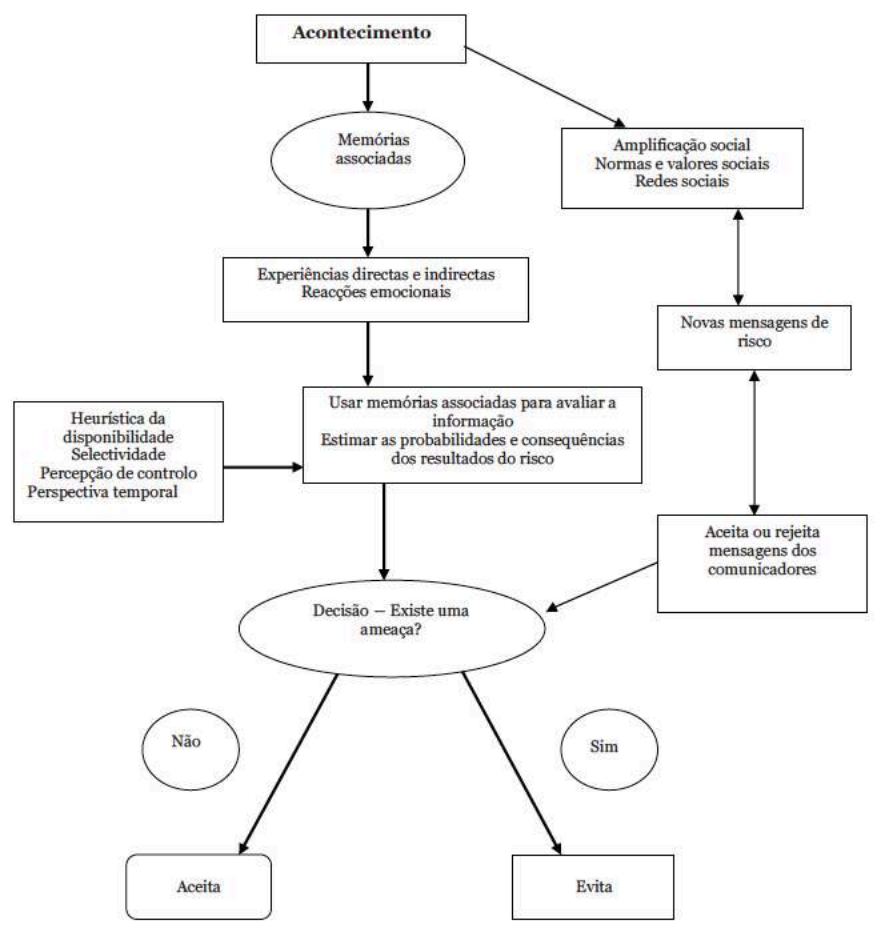

Fonte: ADAPTADO DE EISER (2004: 40).

Douglas e Wildavsky (1982) afirmam que, por norma, os diversos actores sociais fazem uma distinção clara entre os riscos que eles próprios assumem correr voluntariamente e os riscos que lhes são impostos. Os riscos involuntários são mais susceptíveis a serem alvo de rejeição por parte do público, por comparação com os riscos aceites voluntariamente. Outro aspecto importante referenciado na obra destes autores é a indicação de que a distribuição social dos riscos não é efectuada de forma homogénea. Algumas classes ou grupos de pessoas enfrentam mais riscos do que outras. Douglas e Wildavsky (1982) apresentam o seguinte exemplo: Em média, as pessoas mais pobres têm menos saúde do que os ricos, morrem mais cedo e têm mais acidentes. Porém, não se pode afirmar que estas pessoas, incorrendo em maiores níveis de risco nas suas vidas, o façam voluntariamente. Para certos tipos de riscos a relação entre custos suportados e benefícios esperados é um aspecto importante nas tomadas de decisão. Talvez certos indivíduos prefiram estar expostos a determinados riscos laborais ou ambientais, do que estarem desempregados. Quando são colocadas nos «pratos $d a$ balança» as hipóteses de manter um emprego (e suportar certos riscos ocupacionais) ou abandonar o emprego (e deixar de estar exposto aos riscos laborais que lhe estão associados), normalmente opta-se pela preservação do emprego. 0 trabalho é ainda a principal fonte de subsistência da larga maioria da população mundial, isto é, são uma enorme classe-que-vive-do-trabalho (ANTUNES 2008). Por isso, existem determinadas condicionantes sociais, algumas delas de carácter coercivo, que influenciam a aceitabilidade do risco (por exemplo, tenho de aceitar certos riscos para poder ter este emprego, que por sua vez irá permitir sustentar os meus filhos). É verdade que alguns tipos de riscos podem não ser desejados, mas as pessoas têm de fazer opções, 
nomeadamente quando têm de ponderar entre os custos e os benefícios para certos aspectos importantes das suas vidas.

Para além disso, é pertinente considerar que a identificação e a sub ou sobrevalorização de alguns riscos não emergem numa espécie de «vacum social», pelo contrário podem resultar de diferentes segmentos do conhecimento científico ou do saber leigo, de interesses adquiridos ou a conquistar, de questões económicas ou políticas, de distintas valorizações sociais (influenciadas, por exemplo, através do grupo social de pertença), de lutas pelo controlo de determinados tipos de recursos, de estratégias organizacionais ou institucionais e por aí adiante. Deste modo, começamos agora a perceber que a definição daquilo que se pode considerar como um risco no mundo social é um objecto cada vez menos objectivo, e cada vez mais um fenómeno vulnerável a múltiplas interpretações, interesses e subjectividades. A título de exemplo, Perrow (1999) descreve como é que as avaliações de riscos em alguns sistemas complexos são influenciadas por aspectos organizacionais que, por vezes, nada têm a ver com a natureza real dos próprios riscos.

\section{A avaliação probabilística do risco}

O risco enquanto objecto de avaliação probabilística é uma expressão matemática que varia entre o intervalo de 0,0 (impossibilidade de ocorrência) e 1,0 (absoluta certeza de ocorrência), excluindo ambos os referidos valores. No âmbito do estudo das probabilidades Bertrand Russel formula o princípio da indução a partir da associação frequente de eventos. Este autor afirma que se um evento foi observado um número significativo de vezes no passado, isto constitui prova que o mesmo será aplicável em situações futuras. Por oposição a este princípio, Goodman (1954) preconiza que nem todas as regularidades observadas no passado são susceptíveis de originar previsões para o futuro. $\mathrm{Na}$ mesma linha de pensamento podemos encontrar o ensaio protagonizado por Nassim Taleb (2008), onde é referido que efectuar previsões em determinados campos do mundo social pode ser considerado como uma falácia lúdica, visto que o princípio da indução dificilmente pode ser aplicado perante cenários de forte aleatoriedade.

21 Actualmente, o conceito probabilístico do risco é alvo de inúmeras críticas, quer pela sua inadequada aplicação em certas situações, quer pelo uso enviesado que alguns peritos lhe conferem.

«Por muito que qualquer analista de risco saiba que a teoria das probabilidades não pretende fazer previsões sobre cada ocorrência individual, mas sobre um número muito elevado de repetições de ocorrências (pelo que um acontecimento muito provável pode nunca chegar a acontecer, enquanto outro de baixíssima probabilidade pode ocorrer na primeira oportunidade), não é nesta perspectiva modesta e abstracta que as aplicações dessa teoria são apresentadas ao público "leigo", ou são erigidas perante ele em base racional para a tomada de opções» (GRANJO 2006: 1176).

Apesar disso o conceito técnico de risco continua normalmente a ser descrito como a probabilidade de ocorrência de certos eventos, à qual costuma estar associada a magnitude específica das suas consequências (AREOSA 2010). A apresentação do risco em termos de probabilidades pode, em determinadas situações e para certos tipos de público, tornar-se problemático. O leitor veja o seguinte exemplo, apresentado por Gigerenzer (2005: 18): 
«A probabilidade de uma mulher de 40 anos de idade ter cancro da mama é de cerca de $1 \%$. Se tiver cancro da mama, a probabilidade de o resultado do mamograma ser positivo é de $90 \%$. Se não tiver cancro da mama, a probabilidade de o mamograma ser positivo é, ainda assim, de $9 \%$. Qual a probabilidade de uma mulher com resultado positivo numa mamografia ter, efectivamente, cancro da mama?»

23

É possível que depois de ler este pequeno excerto de texto se sinta confuso e provavelmente achará que a probabilidade é de $90 \%$. No excerto abaixo o autor apresenta a mesma informação, só que desta vez utilizando aquilo que o próprio designa por frequências naturais, ou seja, apresenta os dados sem recorrer ao formato de probabilidades.

«Pense num grupo de 100 mulheres. Uma (1) delas tem cancro da mama e é provável que, ao fazer uma mamografia, o resultado do mamograma seja positivo. Das 99 mulheres que não têm cancro da mama, 9 também obterão exames positivos. Assim, um total de 10 mulheres obterá um exame positivo. Das que testam positivo, quantas têm, efectivamente, cancro da mama?» então quantas mulheres com resultado positivo têm, de facto, cancro da mama?

Diversos autores utilizam o desdobramento ou a multiplicação do risco a partir de dois factores principais: baixas consequências versus alta probabilidade e altas consequências versus baixa probabilidade. ${ }^{7}$ Regra geral, esta é a visão dos técnicos que utilizam o modelo probabilístico. Contudo, esta visão estritamente técnica do risco tende a não contemplar as suas dimensões sociais (percepções, sentimentos, receios, etc.), e isto pode causar alguns problemas de aceitação e de legitimação. Segundo Slovic (1987) as pessoas demonstram ter um entendimento mais alargado do risco, contrariando a abordagem unidimensional dos técnicos. ${ }^{8}$ Existem outros aspectos importantes, além do probabilístico, para a abordagem ao risco, tais como: a voluntariedade, a capacidade pessoal para influenciar o risco, a familiaridade com os perigos, a equidade, a controlabilidade e as formas de resposta pública perante um potencial catastrófico (KASPERSON et al., 2000: 232). Assim, a inclusão dos valores sociais deve ser visto como um importante contributo para a definição dos riscos sociais e tecnológicos.

Dentro desta linha de pensamento Granjo (2006) afirma que a noção probabilística do risco não é a única forma racional de observar os cenários de risco ou de ameaça. Para além disso, em certas situações, esta perspectiva pode torna-se inadequada, ou até, exponenciar determinadas fontes de perigo, nomeadamente quando estamos perante tecnologias complexas. Aliás, a utilização da noção probabilística do risco pode até gerar novos perigos, devido à ilusória sensação de segurança que pode provocar sobre os eventuais acontecimentos futuros, visto que estes podem ser mais incertos ou aleatórios do que aquilo que as análises formais parecem indicar. Neste contexto, Granjo (2006) afirma que o actual aprumo técnico de algumas abstracções probabilísticas parecem poder induzir uma ilusão colectiva e excluir a essência do próprio risco, onde aquilo que é incerto parece transformar-se em certeza.

«Não admira então que, conforme há pouco salientei, a generalização da lógica probabilística possa estimular atitudes perigosas e novos perigos. Acontece que, podendo nós deduzir que as potenciais consequências deste fenómeno serão proporcionais à quantidade de factores e interacções desconhecidas que estão presentes em cada caso, os sistemas tecnológicos hipercomplexos e "de risco" serão, precisamente, um dos contextos onde pensar de forma probabilística será mais perigoso» (GRANJO 2006: 1177). 
$\mathrm{Na}$ nossa história recente parece ter ficado bem patente que acidentes como os de Seveso, Bhopal, Chernobyl e Fukushima demonstraram as suas consequências devastadoras para milhares de seres humanos e/ou para o meio ambiente. Probabilisticamente falando estes eventos estariam classificados muito perto do zero; porém, apesar da sua probabilidade residual todos sabemos que eles aconteceram. No ponto seguinte deste trabalho iremos precisamente centrar grande parte da nossa atenção no debate dos cenários de risco que estão a montante deste tipo de eventos catastróficos. ${ }^{9}$

\section{Riscos tecnológicos e sociedades de risco: o caso dos sistemas complexos com potencial catastrófico}

28 A percepção sobre o papel da tecnologia na sociedade foi sofrendo algumas alterações desde a revolução industrial. Durante este período a tecnologia foi quase sempre valorizada de forma positiva (embora também houvesse o receio de que poderia «roubar» os empregos), visto que se pensava que ela permitiria o progresso e o desenvolvimento social, incluindo a libertação do homem dos trabalhos mais fustigantes. A crença nos benefícios da tecnologia era vista como uma forma de emancipação do homem, cuja finalidade seria proporcionar-lhe a felicidade. Porém, no período pós Segunda Guerra Mundial começaram a surgir os primeiros movimentos cépticos ou críticos ao papel da tecnologia, não à tecnologia em si mesma, mas sim às suas formas de utilização e ao seu real distanciamento dos benefícios para a humanidade (MARCUSE 1982). É dentro deste contexto algo ambíguo que pretendemos debater os riscos tecnológicos e explorar os seus efeitos negativos ou perversos.

Uma das perspectivas que melhor debateu o papel da tecnologia na sociedade foi a designada teoria crítica da escola de Frankfurt, a qual visava (do ponto de vista ideológico) a superação das injustiças sociais e a emancipação do homem, dado que a sociedade tecnológica era entendida como um sistema de dominação social. Esta perspectiva foi desenvolvida por Marcuse onde era sublinhado que o homem se transformou num ser dominado pela tecnologia. A proposta deste autor vai no sentido de reformular todo o papel da tecnologia, não no sentido de a secundarizar, mas antes de a colocar ao serviço do homem (para que ela possa adquirir um carácter libertador). De certa forma a teoria de Marcuse teve um carácter premonitório sobre alguns efeitos nefastos da tecnologia, embora o autor não tenha propriamente identificado os riscos tecnológicos industriais, os quais só viriam a ser verdadeiramente compreendidos a posteriori. Verificou-se então, mais tarde, que alguns tipos de tecnologias deram origem a acidentes catastróficos. ${ }^{10}$ Algumas tecnologias criadas pelo homem possuem um potencial de risco tão elevado, em termos destrutivos, que talvez fosse útil repensar se os benefícios que indiscutivelmente acarretam, justificam os riscos nefastos que lhes estão associados (PERROW 1999). Esta questão deveria estar, ainda mais, na base de um sério e amplo debate socio-político ao nível global. É dentro deste contexto que Garcia refere o seguinte:

«Deixou de ser descabido interrogar se uma determinada tecnologia contribui para aumentar ou diminuir a crise ambiental, as condições de justiça na sociedade ou mesmo para alterar de forma extrema a natureza da condição humana tal como a temos conhecido; o lastro do nosso olhar teima fixar-se na sua mera utilidade e contribuição económica» (GARCIA 2003: 80). 
30 permitiram o desenvolvimento de uma indústria complexa. Por sua vez, esta aliança possibilitou a emergência de novos riscos tecnológicos. Esta condição leva o autor a afirmar que vivemos actualmente numa civilização do risco. Regra geral, os novos riscos de origem tecnológica, quando são percebidos pelo público (enquanto tal), não são pautados por consensos sociais, pelo contrário, podem ser uma fonte de controvérsia entre os agentes produtores dos riscos e o público que a eles fica exposto (este último conjunto de actores é designado por Palmlund como «vítimas»). Segundo Perrow (1999: 310) os riscos oriundos das tecnologias mais arriscadas não «nascem» equitativamente para as diferentes classes sociais. Esta situação remete-nos para a ancestral questão do sacrifício da maioria da população para assegurar a qualidade de vida de algumas elites sociais (PALMLUND 1992). No caso concreto dos riscos tecnológicos alguns agentes sociais (as «vítimas») têm de suportar os custos do progresso tecnológico e é aqui que está situado o centro do drama e da controvérsia social (PALMLUND 1992). Por vezes, o público olha com desconfiança para os resultados das avaliações de riscos promovidas pelos grupos mais poderosos que, normalmente, tentam suavizar os efeitos de certos riscos com elevado potencial nocivo ou catastrófico, podendo estas situações transformar-se em conflitos. Embora os conflitos sobre os riscos tecnológicos sejam caracterizados por ciclos de vida, onde a sua visibilidade social passa por momentos distintos, oscilando entre ciclos de forte agitação ou de tranquilidade moderada (PALMLUND 1992: 206). A própria tecnologia também é determinada por ciclo de vida, ${ }^{11}$ embora estes ciclos sejam no mundo hodierno cada vez mais curtos.

Se, por um lado, os avanços da ciência e da tecnologia permitiram controlar determinados tipos de riscos, nomeadamente algumas doenças infecto-contagiosas, por outro lado, deram origem a novos cenários de risco, envolvendo, por exemplo, agentes químicos, biológicos e radioactivos (como é o caso das centrais nucleares). ${ }^{12}$ Esta ideia é também expressa por Beck (1992) quando refere que o desenvolvimento e a produção tecnológica deram origem à criação de novos tipos de riscos. Numa linha de pensamento similar, Delicado e Gonçalves (2007: 695) sugerem que as novas formas de risco estão vinculadas aos modos de produção da riqueza na «modernidade avançada», sendo estas, em muitos casos, desencadeadas pela utilização de tecnologias. Duclos (1989, citado em DOUGLAS 1992) denuncia dois tipos de medos referentes aos riscos tecnológicos; o primeiro está ligado ao medo de morrer devido a desastres de origem tecnológica, enquanto o segundo, associa o medo a uma alegada opressão por parte de quem controla as novas tecnologias. Na perspectiva de Douglas e Wildavsky (1982) alguns riscos tecnológicos assumem um papel de destaque na nossa mente, devido à ansiedade e incerteza que produzem. Paralelamente, Theys (1987) refere que a análise de riscos tecnológicos é um factor importante para compreender as diversas vulnerabilidades sociais do mundo moderno.

Até aqui temos sublinhado essencialmente alguns dos aspectos desfavoráveis associados à tecnologia. Todavia, segundo Fischhoff et al. (1984), os riscos decorrentes das tecnologias modernas não podem ser vistos apenas no prisma das consequências negativas que produzem, pois ninguém produz as tecnologias se estas não gerarem benefícios para alguém e ninguém as consegue produzir sem um determinado investimento ou custo (económico). Já referimos que os riscos tecnológicos podem provocar grandes desastres, potencialmente fatais e/ou devastadores em termos de vidas humanas ou bens materiais (AREOSA 2012b), mas, normalmente, também nos 
trazem - de forma paradoxal - maior qualidade de vida. Metaforicamente a tecnologia pode ser vista como um «veneno» que, simultaneamente, pode transportar o "antídoto» para alguns males contemporâneos. Quando se decide adoptar uma determinada tecnologia temos de aceitar o seu leque de características (benefícios e/ou prejuízos), visto que ambos vêem na mesma «embalagem». Otway (1992) refere que os riscos tecnológicos não são apenas percepcionados em cenários abstractos, eles fazem parte de um conjunto mais vasto de atributos e considerações sociais que podem levar as pessoas a aceitá-los ou rejeitá-los.

Na perspectiva de Daniel Kahneman (2012) o mundo que é idealizado nas nossas cabeças não é uma réplica exacta da realidade. Nós, enquanto espécie, somos bastante vulneráveis a construir e imaginar cenários ilusórios a partir de emoções, preferências e sentimentos. As heurísticas do afecto «ajudam-nos» nessa tarefa, dado que são susceptíveis de produzir múltiplos enviesamentos. Numa investigação relatada pelo autor verificou-se que existia uma elevada correlação negativa entre o nível de benefício e o nível de risco que os respondentes atribuíam a determinadas tecnologias. Deste modo, quando as pessoas tinham um sentimento positivo em relação a certas tecnologias, referiam-se a elas como contendo diversos benefícios e poucos riscos; pelo contrário, quando tinham uma preferência negativa por uma qualquer tecnologia, tendiam a ver apenas suas desvantagens e poucos benefícios lhes surgiam na mente. A parte mais surpreendente desta experiência surgiu quando os investigadores, após os respondentes terem completado o inquérito inicial, lhes disponibilizaram argumentos a favor das tecnologias. A alguns sujeitos observados foram apresentados diversos argumentos que destacavam os benefícios de certas tecnologias; a outros, foram-lhes dados argumentos que sublinhavam os seus baixos riscos. Aquilo que os investigadores descobriram foi o seguinte: mesmo as pessoas que apenas tinham recebido informação sobre os benefícios das tecnologias acabaram por modificar positivamente as suas crenças em relação aos riscos dessas mesmas tecnologias. Apesar de estas pessoas não terem recebido qualquer informação sobre os riscos associados a essas tecnologias, passaram a vê-las como menos arriscadas. A situação inversa também se verificou, ou seja, a quem foi dito que uma determinada tecnologia tinha poucos riscos, acabou por formar uma opinião mais favorável sobre os seus benefícios. $O$ autor chega à seguinte conclusão:

«A heurística do afecto simplifica as nossas vidas, ao criar um mundo que é muito mais arrumado do que a realidade. As boas tecnologias têm baixos custos no mundo imaginário que habitamos, as más tecnologias não têm benefícios e todas as decisões são fáceis. No mundo verdadeiro, claro, enfrentamos com frequência dolorosos compromissos entre benefícios e custos» (KAHNEMAN 2012: 189).

Já referimos anteriormente que na óptica de Ulrich Beck (1992) afirma que o desenvolvimento da ciência e da tecnologia permitiu o progresso económico das sociedades ocidentais; porém, o fruto desse desenvolvimento contribuiu para a emergência de novos riscos. O risco, na perspectiva de Beck, define as sociedades modernas e foi por este motivo que o autor as designou como sociedades de risco. A noção de risco surge associada ao conceito de modernização reflexiva. «Risk may be defined as a systematic way of dealing with hazards and insecurities induced and introduced by modernization itself. Risks, as opposed to older dangers, are consequences which relate to the threatening force of modernization and to its globalization of doubt. They are politically reflexive» (BECK 1992: 21). 

efeitos nefastos dos processos de globalização e do desenvolvimento tecnológico. Mas, de facto, ninguém pode escapar às suas consequências, visto que estamos todos retidos na teia dos riscos tecnológicos globalizados. 0 autor afirma que, de certa forma, vivemos num período em que a responsabilidade está diluída por diversos segmentos da sociedade. Os decisores políticos afirmam que não são responsáveis pelos efeitos dos riscos tecnológicos, no máximo regulam o seu desenvolvimento. Os cientistas dizem que apenas geram novas tecnologias, mas que não decidem sobre a forma como elas são utilizadas. Os empresários preconizam que apenas vão ao encontro das necessidades do consumidor. É por este motivo que o autor designa esta situação como uma irresponsabilidade organizada. Parece que a sociedade actual se tornou num laboratório onde ninguém pretende assumir a responsabilidade pelo resultado das «experiências» realizadas.

Uma das teses centrais de Beck revela que os alguns dos novos riscos deixaram de poder ser pensados enquanto fenómenos locais, circunscritos a uma determinada área ou situação, visto que assumiram um carácter global. A abordagem da sociedade de risco teve um enorme impacto social na sua fase inicial, embora, posteriormente, fosse também alvo de diversas críticas à sua concepção teórica (MOL e SPAARGAREN 1993; LASH 2000; ELLIOTT 2002). ${ }^{13} \mathrm{~A}$ sociedade de risco emerge em resposta à obsolescência da sociedade industrial, onde também se verifica a erosão de alguns papéis sociais (BECK et al., 2000). A terminologia de sociedade de risco designa essencialmente uma condição das sociedades contemporâneas, nas quais os riscos sociais, individuais, políticos e económicos tendem, de forma crescente, a escapar à protecção, controlo e monitorização da sociedade industrial. Segundo Beck, existem dois estádios distintos para estas duas realidades sociais, isto é, a sociedade de risco sucede à sociedade industrial. A transição da sociedade industrial para a sociedade de risco é irreversível e Beck vai designar este período como modernidade reflexiva ou reflexividade. ${ }^{14}$ Assim, num primeiro momento, os riscos, as ameaças e os efeitos perversos das sociedades industriais, coexistem de igual forma, mas não fazem parte da agenda dos media, nem da discussão pública, nem tampouco se colocam no centro dos debates e conflitos políticos; enquanto num segundo momento, a discussão sobre os efeitos dos riscos passam a ocupar esses espaços. Os media assumem um papel importante nas sociedades do risco.

Num primeiro estádio predominam ainda as características mais marcantes da sociedade industrial, onde as ameaças ou riscos sobre o público são desvalorizadas e não legitimadas pelos diversos centros de decisão e de poder, os quais lhe atribuem um valor insignificante, designando-os, regra geral, como riscos residuais fruto das vivências quotidianas. Num segundo estádio de desenvolvimento, existe uma consciencialização real das situações de risco, em que os perigos tendem a tornar-se o centro do debate político, público e privado. Segundo Beck, as organizações actuais tornaram-se, simultaneamente, produtoras e consumidoras das múltiplas formas e fontes de risco que não conseguem controlar.

«A transição do período industrial para o período do risco da modernidade ocorre de modo indesejado, invisível e compulsivo no surgimento do dinamismo autonomizado da modernização, seguindo o modelo dos efeitos secundários latentes. Virtualmente, podemos dizer que as constelações da sociedade de risco são produzidas porque as certezas da sociedade industrial (o consenso em torno do progresso ou a abstracção de efeitos e acidentes ecológicos) dominam o pensamento 
e a acção das pessoas e das instituições da sociedade industrial. A sociedade de risco não é uma opção passível de aceitação ou rejeição no curso de disputas políticas. Surge na continuidade dos processos de modernização autonomizada, que são cegos e surdos em relação aos seus próprios efeitos e ameaças» (BECK et al., 2000: 5).

38 A obra de Perrow (1999), cuja primeira edição foi publicada em meados dos anos oitenta, é uma das abordagens sistémicas mais proeminentes e apresenta um diagnóstico sobre a temática dos riscos tecnológicos associados aos grandes acidentes, bem como os factores que lhe estão subjacentes. Segundo as suas próprias palavras o tema central do seu livro é o poder e não o risco - o poder das elites em impôr determinados tipos de riscos sobre muitos, para o benefício de poucos. Paralelamente a esta discussão podemos afirmar que os sistemas tecnológicos de alto risco são o seu objecto de análise privilegiado, abordando realidades organizacionais tão distintas como: centrais nucleares, plataformas petrolíferas, marinha, indústria química, aviação, missões espaciais ou engenharia genética. Estas e outras actividades (não referenciadas) possuem um potencial catastrófico passível de resgatar centenas de vidas humanas e de afectar milhares de outras, além dos prejuízos que podem gerar ao nível material, social, económico e ambiental (neste último caso, designado na literatura como ecocídio). Seguramente que este será um dos motivos pelo qual o estudo dos riscos e dos grandes acidentes ganhou alguma visibilidade social (AREOSA 2009; 2010).

39 Na óptica de Perrow (1999) alguma da tecnologia que foi desenvolvida a partir da década de setenta caracteriza-se por ser extremamente complexa. Este tipo específico de tecnologia foi designado pelo autor como sistemas complexos altamente interligados. As disfunções de um sub-sistema podem originar o designado efeito dominó, podendo dar origem a acidentes sistémicos, em que uma parte significativa do sistema ou mesmo todo o sistema é destruído. Os acidentes deste tipo acarretam normalmente elevados prejuízos. Perrow revela alguns exemplos de acidentes deste tipo ligados à engenharia aeronáutica, às centrais nucleares e à indústria química. As avaliações de riscos tecnológicos não devem apenas considerar estes riscos em si mesmo, visto que eles estão incluídos num sistema social e humano. Algumas análises de riscos subestimam factores decisivos dentro das organizações, nomeadamente o inevitável erro humano, ${ }^{15}$ a diluição da responsabilidade dentro das cadeias hierárquicas, a pressão sobre a produtividade dos trabalhadores (muitas vezes anulando ou reduzindo os níveis de segurança), a utilização de sistemas de controlo obsoletos ou inadequados, as diferentes formas de perceber e interpretar os riscos organizacionais e as situações excepcionais de trabalho (que exponenciam os riscos e consequentemente a ocorrência de acidentes) (AREOSA 2012c).

40 Na perspectiva de Perrow (1999: 23) a essência dos acidentes de origem tecnológica está na interacção de múltiplas falhas cuja sequência não é directamente antecipável. Algumas destas interacções inesperadas possuem um potencial catastrófico e autodestrutivo do próprio sistema e são estas interacções singulares que provocam normalmente os grandes acidentes, decorrente de circunstâncias raras e muito específicas. A dificuldade em antecipar e prevenir estas situações deve-se ao número quase infinito de possíveis interacções entre falhas nos diversos componentes dos sistemas complexos, embora a interacção de falhas com potencial catastrófico seja supostamente reduzida, devido, em parte, aos dispositivos de segurança. ${ }^{16}$ Contudo, isto não significa que em condições excepcionais os acidentes não possam ocorrer. Talvez seja o reduzido número de falhas (em articulação umas com as outras) com potencial 
catastrófico o motivo pelo qual os acidentes sistémicos são eventos relativamente raros. A maior preocupação relacionada com os acidentes tecnológicos de larga-escala acaba por estar situada nos danos ou prejuízos causados e não tanto na frequência da sua ocorrência. É precisamente por isso que não devemos descurar a paranóia construtiva, debatida por Jared Diamond (2013).

\section{Considerações finais}

A tecnologia é normalmente «indisciplinada» e as suas «caixas negras» são, por vezes, difíceis de decifrar (WYNNE 1988). Na perspectiva de Paul Virilio (1983) toda e qualquer tecnologia é susceptível de produzir acidentes. $\mathrm{O}$ autor refere os seguintes exemplos: A invenção dos navios deu origem aos naufrágios; a criação da locomotiva possibilitou os descarrilamentos; e a construção de aviões permitiu os desastres aéreos. Por este motivo, a continuidade do desenvolvimento tecnológico implica que teremos de pensar mais nas suas consequências negativas (e não apenas nos benefícios que nos oferecem), incluindo o tipo de acidentes que podem provocar. É pertinente lembrar que os acidentes são uma característica inevitável do universo (GREEN 1997). As tecnologias complexas incorporam determinadas incertezas «mal compreendidas» que não conseguimos controlar, nomeadamente as suas interacções com o sistema social. No entanto, parece que ainda estamos longe de aceitar esta condição com alguma humildade e seriedade. As indefinições dos sistemas socio-técnicos transformam as sociedades actuais em verdadeiros laboratórios experimentais, cujas consequências podem ser imprevisíveis (BECK 1992).

A omnipresença dos riscos tecnológicos nos sistemas complexos é, em grande medida, a antecâmara para os acidentes (AREOSA 2009). Não existem organizações isentas de risco, logo, os acidentes são eventos inevitáveis e passíveis de ocorrer a qualquer momento. Porém, isto não significa que a prevenção não seja útil, mas é pertinente considerar que até a «melhor» estratégia de prevenção tem os seus limites. Segundo Perrow (1999) as organizações que possuem sistemas tecnológicos complexos ou ultracomplexos já provaram que não dispõem de condições para eliminar todos os acidentes. Contudo, isto não significa obrigatoriamente que estejamos perante organizações «incompetentes» ou incapazes de controlar os riscos das suas actividades, significa acima de tudo que a segurança das organizações revela limites inerentes à sua própria condição. Muitas vezes, ignoramos a nossa própria ignorância, mas isso torna-se perigoso.

De certo modo, os acidentes são produzidos socialmente e tornaram-se num acontecimento «normal», devido à elevada complexidade de alguns sistemas e às suas interacções não-lineares. Isto denota que não podemos pensar em prevenir todos os acidentes, caso contrário será uma visão irrealista e utópica sobre a realidade das organizações. Voltamos a sublinhar que toda a teoria Perrow (1999) reforça a ideia de que os acidentes são acontecimentos inevitáveis e a sua prevenção, em certos contextos, torna-se virtualmente impossível de realizar. Mesmo a experiência de acidentes anteriores pouco pode acrescentar à prevenção de futuros acidentes, visto que o alinhamento das suas causas e circunstâncias é normalmente singular ou quase irrepetível. Sem dúvida que as tecnologias nos oferecem normalmente um lado benéfico e outro prejudicial (julgamos que este aspecto é relativamente consensual). Aquilo que se torna complexo e problemático no debate sobre algumas tecnologias é a 
decisão política de aceitá-las ou rejeitá-las. Kahneman (2012) já nos demonstrou que a forma como olhamos para as tecnologias nem sempre é tão racional e objectiva como supomos.

\section{BIBLIOGRAFIA}

ADAM B. e LOON J. van, 2000, «Introduction: Repositioning risk; the challenge for social theory», in B. Adam; U. Beck e J. van Loon (eds.), The risk society and beyond. Critical issues for social theory. Londres, Sage, pp. 1-32.

ADAMS J., 2005, Big ideas: risk. Londres, New Scientist.

AMALBERTI R., 2006, «Optimum system safety and optimum system resilience: Agonistic or antagonistic concepts?», in E. Hollnagel; D. D. Woods; N. Leveson (eds.), Resilience engineering: Concepts and precepts. Aldershot, UK, Ashgate Publishing Co., pp. 253-274.

ANTUNES Ricardo, 2008, «Desenhando a nova morfologia do trabalho: As múltiplas formas de degradação do trabalho», Revista Crítica de Ciências Sociais (Coimbra), n.ำ 83, pp. 19-34.

AREOSA J., 2008, «Risco e análise de riscos: Contributos para a sua conceptualização», Guimarães, Colóquio internacional de segurança e higiene ocupacionais, SHO, pp. 45-50.

AREOSA J., 2009, «Do risco ao acidente: Que possibilidades para a prevenção?», Revista Angolana de Sociologia (Luanda), n.․ 4, pp. 39-65.

AREOSA J., 2010, «O risco nas ciências sociais: Uma visão crítica ao paradigma dominante», Revista Angolana de Sociologia (Luanda), n.5/6, pp. 11-33.

AREOSA J., 2011, «Riscos ocupacionais da Imagiologia: Estudo de caso num hospital português», Tempo Social (São Paulo), vol. 2, n.․2 23, pp. 297-318.

AREOSA J., 2012a, «As perceções de riscos dos trabalhadores: Qual a sua importância para a prevenção de acidentes de trabalho?», in H. V. Neto, J. Areosa e P. Arezes (eds.), Impacto social dos acidentes de trabalho, Vila do Conde, Civeri Publishing, pp. 65-97.

AREOSA J., 2012b, «O contributo das ciências sociais para a análise de acidentes maiores: Dois modelos em confronto», Análise Social, (Lisboa), n.․ 204, pp. 558-584.

AREOSA J., 2012c, O lado obscuro dos acidentes de trabalho: Um estudo de caso no setor ferroviário. Famalicão, Editora Húmus.

AREOSA J., 2013, «Christophe Dejours e a psicodinâmica do trabalho», Revista Portuguesa de Psicanálise (Lisboa), vol. 2, n. 33, pp. 29-41. 2014, «As perceções de riscos ocupacionais no sector ferroviário», Sociologia, Problemas e Práticas (Lisboa), n.ำ 75, pp. 83-107.

AREOSA J. e DWYER T., 2010, «Acidentes de trabalho: Uma abordagem sociológica», Configurações

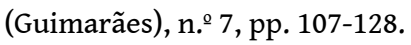

BAUMAN Z., 1991, Modernity and ambivalence. Oxford, Polity.

BECK U., 1992, Risk society. Towards a new modernity. Londres, Sage. 
BECK U., 2001, «A ciência é causa dos principais problemas da sociedade industrial». Entrevista concedida a Antoine Reverchon, do «Le Monde», in Folha de São Paulo (São Paulo), 20 de Novembro.

BECK U., 2013, «Viver na sociedade do risco mundial e lidar com ele», in D. Innerarity e J. Solana (orgs.), A humanidade ameaçada: A gestão dos riscos globais. Lisboa, Teodolito, pp. 31-39.

BECK U.; GIDDENS A. e LASH S., 2000, Modernização reflexiva: Política, tradição e estética na ordem social moderna. Oeiras, Celta Editora.

BERNSTEIN P., 1996, Against the gods: The remarkable story of risk. New York, Wiley.

CARAPINHEIRO G., 2001, «A globalização do risco social», in B. S. Santos (org.), Globalização: Fatalidade ou utopia. Porto, Afrontamento, pp. 197-229.

COVELLO V. e MERKHOFER M., 1993, Risk assessment methods, approaches for assessing health and environmental risks. New York, Plenum Press.

DEAN M., 1999, «Risk, calculable and incalculable», in D. Lupton (ed.), Risk and sociocultural theory: New directions and perspectives. Cambridge, Cambridge University Press, pp. 131-159.

DEJOURS C., 2013, «A sublimação, entre o sofrimento e prazer no trabalho», Revista Portuguesa de Psicanális (Lisboa), vol. 2, n. 33, pp. 9-28.

DELICADO A. e GONÇALVES M. E., 2007, «Os portugueses e os novos riscos: Resultados de um inquérito», Análise Social (Lisboa), n.․184, pp. 687-718.

DIAMOND J., 2013, O mundo até ontem. O que podemos aprender com as sociedades tradicionais. Lisboa, Temas e Debates.

DOUGLAS M., 1992, Risk and blame: Essays in cultural theory. Londres, Routledge.

DOUGLAS M. e WILDAVSKY A., 1982, Risk and culture: An essay on the selection of technological and environmental dangers. Berkeley (CA), University of California Press.

EISER J. R., 2004, Public perception of risk, Report prepared for Foresight, Office of Science and Technology, UK.

ELLIOTT A., 2002, «Beck’s sociology of risk: A critical assessment», Sociology, vol. 36, n. 2, pp. 293-315.

EVANS-PRITCHARD E. E., 1937, Witchcraft, oracles and magic among the Azande. Oxford, Clarendon Press.

EWALD F., 1991, «Insurance and risk», in G. Burchell; C. Gordon e P. Miller (eds.), The Foucault effect. Studies in governmentality with two lectures by and an interview with Michel Foucault. Londres, Harvester Wheatsheaf, pp. 197-210.

FISCHHOFF B.; WATSON S. e HOPE C., 1984, «Defining risk», Policy Sciences, n.․ 17, pp. 123-139.

GARCIA J. L., 2003, «A crítica política da tecnologia como tarefa da sociologia contemporânea», Trajectos (Lisboa), n.․ 2, pp. 75-81.

GARDNER D., 2008, Risco: A ciência e a política do medo. Rio de Janeiro, Odisseia Editorial.

GIDDENS A., 1994, Modernidade e identidade pessoal. Oeiras, Celta Editora.

GIDDENS A., 1998, As consequências da modernidade. Oeiras, Celta Editora.

GIDDENS A., 2000, O mundo na era da globalização. Lisboa, Editorial Presença.

GIGERENZER G., 2005, Calcular o risco. Aprender a lidar com a incerteza. Lisboa, Gradiva. 
GOODMAN N., 1954, Fact, fiction and forecast. Cambridge, Harvard University Press.

GRANJO P., 2006, «Quando o conceito de “risco" se torna perigoso», Análise Social (Lisboa), n.․ 181, pp. 1167-1179.

GREEN J., 1997, Risk and misfortune: The social construction of accidents. Londres, Routledge.

GUZZO M., 2004, «Corpo em risco», Athenea Digital, n.․ 6, pp. 1-10.

HESPANHA P. e CARAPINHEIRO G. (orgs.), 2002, Risco social e incerteza: Pode o estado social recuar mais?, Porto, Afrontamento.

KAHNEMAN D., 2012, Pensar depressa e devagar. Lisboa, Temas e Debates.

KAPLAN S. e GARRICK B. J., 1981, «On the quantitative definition of risk», Risk Analysis, n. 1, pp. 11-27.

KASPERSON R., et al., 2000, «The social amplification of risk: A conceptual framework», in P. Slovic, The perception of risk. Londres, Earthscan Publications, pp. 232-245.

LAGADEC P., 1981, La civilisation du risque: Catastrophes technologiques et responsabilité sociale. Paris, Seuil.

LAPORTE T. e CONSOLINI P., 1991, «Working in practice but not in theory: Theoretical challenges of "High-Reliability Organizations"», Journal of Public Administration Research and Theory, n. 1, pp. 19-48.

LASH S., 2000, «Risk culture», in B. Adam; U. Beck e J. Van Loon (eds.), The risk society and beyond. Critical issues for social theory. Londres, Sage, pp. 47-63.

LUHMANN N., 1993, Risk: A sociological theory. New York, Aldine de Gruyter.

LUPTON D., 2003, Risk. Londres, Routledge.

MARCUSE H., 1982, A ideologia da sociedade industrial. O homem unidimensional. Rio de Janeiro, Zahar Editores.

MARTINS H., 1998, «Risco, incerteza e escatologia. Reflexões sobre o experimentum mundi em curso», Episteme - Revista da Universidade Técnica de Lisboa, n.ำ1, pp. 99-121.

MELA A.; BELLONI M. e DAVICO L., 2001, A sociologia do ambiente. Lisboa, Editorial Estampa.

MOL A. e SPAARGAREN G., 1993, «Environment, modernity and the risk-society: The apocalyptic horizon of environmental reform», International Sociology, vol. 4, n.․ 8, pp. 431-459.

NETO H. V., 2013, Construção social do risco e da segurança do trabalho em contexto organizacional. Vila do Conde, Civeri Publishing.

OTWAY H., 1992, «Public wisdom, expert fallibility: Toward a contextual theory of risk», in S. Krimsky e D. Golding (eds.), Social theories of risk. Westport (CT), Praeger Press, pp. 215-228.

PALMLUND I., 1992, «Social drama and risk evaluation», in S. Krimsky e D. Golding (eds.), Social theories of risk. Westport (CT), Praeger Press, pp. 197-212.

PERROW C., 1999, Normal accidents: living with high-risk technologies. New Jersey, Princeton University Press.

RAJAN R., 2002, «Disaster, development and governance: Reflections on the "Lessons" of Bhopal», Environmental Values, n.․ 11, pp. 369-394.

RASMUSSEN J., 1997, «Risk management in a dynamic society: A modeling problem», Safety

Science, n.․ 27, pp. 183-213. 
REASON J., 1990, Human error. Cambridge, Cambridge University Press.

REBELO F., 2005, «Riscos naturais. Problemática da sua definição e adaptação aos principais elementos da teoria do risco», in C. Guedes Soares et al. (eds.), Análise e gestão de riscos, segurança e fiabilidade. Lisboa, Edições Salamandra, vol. I, pp. 301-315.

RENN O., 1992, «Concepts of risk: a classification», in S. Krimsky e D. Golding (orgs.), Social theories of risk. Westport (CT), Praeger Press, pp. 53-79.

SENNETT R., 2001, A corrosão do carácter: As consequências pessoais do trabalho no novo capitalismo, Lisboa, Terramar.

SAGAN S., 1993, The limits of safety: Organizations, accidents, and nuclear weapons. Princeton (NJ), Princeton University Press.

SLOVIC P., 1987, «Perception of risk», Science, n. 236, pp. 280-285.

SLOVIC P., 2001, «The risk game», Journal of Hazardous Materials, n.. 86, pp. 17-24.

SPINK M., 2001, «Trópicos do discurso sobre risco: Risco-aventura como metáfora na modernidade tardia», Cadernos de Saúde Pública, vol. 6, n.․17, pp. 1277-1311.

STARR C., 1969, «Social benefit versus technological risk», Science, n.․ 165, pp. 1232-1238.

TALEB N. N., 2008, 0 cisne negro. 0 impacto do altamente improvável. Amadora, Publicações Dom Quixote.

THEYS J., 1987, «La société vulnerable», in V. Cohen et al., La société vulnerable. Paris, Presses de L’École Normale Supérieure.

VIRILIO P., 1983, Pure war. New York, Semiotext(e).

WYNNE B., 1988, «Unruly technology: Practical rules, impractical discourses and public understanding», Social Studies of Science, vol. 1, n.․ 18, pp. 147-167.

\section{NOTAS}

1. Outras investigações sobre a etimologia do risco sugerem que esta palavra possa ter tido origem num outro termo italiano: resecare (cujo significado é cortar). Esta expressão era também utilizada para descrever geografias irregulares e «cortantes», relacionadas com as viagens marítimas, tais como rochas submersas ou bancos de areia que cortavam ou danificavam os cascos dos navios (GUZZO 2004).

2. Particularmente após o terramoto de Lisboa ocorrido no ano de 1755 (AREOSA 2008).

3. Curiosamente, no estudo de Evans-Pritchard (1937) sobre os Azande, observou-se que, no conjunto de crenças deste povo, as adversidades quotidianas dos seus membros (sejam elas quais forem) eram sempre atribuídas a actos de bruxaria, logo a essência dos acontecimentos negativos são imputados aos outros membros da sociedade (esta ideia faz lembrar a expressão de Jean Paul Sartre, na peça intitulada "A porta fechada», onde o autor preconizava que "o inferno são os outros»). Assim, os potenciais castigos divinos na época pré-industrial, enquanto fonte de risco do mundo ocidental, encontram paralelo neste povo africano através da feitiçaria.

4. Tal como iremos frisar adiante, a abordagem probabilística é hegemónica nas apreciações técnicas do risco, mas esta visão supostamente objectiva é susceptível de originar interpretações enviesadas ou distorcidas.

5. Aqui apresentamos mais um exemplo da sua definição conceptual: «A noção de risco, devo acentuar, é inseparável das ideias de probabilidade e de incerteza. Não se pode dizer que alguém enfrenta um risco quando o resultado da acção está totalmente garantido [...]. Risco não é o mesmo que acaso ou 
perigo. 0 risco refere-se a perigos calculados em função de possibilidades futuras. Só tem uso corrente numa sociedade orientada para o futuro, uma sociedade que vê o futuro precisamente como um território a ser conquistado ou colonizado» (GIDDENS 2000: 32 e 33).

6. Estas duas definições revelam algumas semelhanças com os conceitos de risco exterior e risco provocado, propostos por Giddens (2000).

7. São também utilizadas por LaPorte e Consolini (1991: 23) as noções de «alto-perigo» e «baixorisco» para definir e caracterizar as organizações de alta fiabilidade; quanto a nós, estas noções são contraditórias e não devem ser utilizadas, em simultâneo, para caracterizar a mesma realidade, visto que os riscos decorrem dos perigos, logo quando um perigo é alto, por dedução o risco tenderá também a sê-lo (AREOSA 2012b).

Ainda a propósito do desdobramento do risco em altas consequências versus baixa probabilidade, verificamos que esta noção já está implícita em alguns aspectos das sociedades tradicionais. Num extraordinário trabalho de campo levado a cabo pelo geógrafo Jared Diamond (2013), realizado na Nova Guiné, o autor observou que os nativos evitavam de forma quase paranóica alguns riscos de baixa probabilidade de ocorrência. Entre outras situações, Diamond verificou que os novaguineenses que o acompanhavam na sua pesquisa de campo se recusavam de forma peremptória a dormir em volta de uma árvore morta, apesar da insistência do geógrafo (num determinado dia) em afirmar que aquele seria o melhor local para pernoitar. Mas afinal qual foi o motivo que levou os nativos nova-guineenses a resistirem ao cumprimento de uma indicação dada pelo responsável máximo da expedição? Muito simplesmente porque sabem que as árvores mortas, mais tarde ou mais cedo, caem! Apesar de a probabilidade de uma árvore morta cair precisamente nas escassas horas nocturnas (naquele dia específico e durante o período de sono) ser muito baixa, eles sabem que se isso acontecer as consequências podem ser as piores (lesões muito graves ou morte por esmagamento). Esta situação não inibe os nova-guineenses a circularem pela floresta (onde existem muitas árvores mortas), mas implica uma espécie de esconjuração do risco e, simultaneamente, uma precaução vincada através da redução temporal na exposição ao perigo. Esta atitude preventiva dos nova-guineenses foi designada por Diamond como paranóia construtiva.

8. Tendo como pano de fundo a linguagem técnica de peritos ou especialistas sobre o risco, verifica-se que existe uma certa tendência para este grupo de agentes sociais poder apresentá-lo de uma forma unidimensional, como por exemplo, a estimativa do número de mortos durante um determinado tempo de exposição. «The risk measure used here is the statistical probability of fatalities per hour of exposure of the individual to the activity considered» (STARR 1969: 165). Porém, para a maioria da população não especialista esta descrição unidimensional revela alguma falta de sentido prático, sendo as percepções de riscos do público leigo normalmente caracterizadas pela multidimensionalidade de factores apresentados. «People's perception and attitudes are determined not only by the sort of unidimensional statistics used in these tables (risk per hour of exposure, annual probability of death) but also by the variety of quantitative and qualitative characteristics reflected by our analyses. To many people, statements such as "the annual risk of living near a nuclear power plant is equivalent to the risk of riding an extra three miles in an automobile" give inadequate consideration to the important differences in the nature of risks from these two technologies. In short, "riskiness" means more to people thanb "expected number of fatalities"》 (SLOVIC 1987: 285).

9. Caso o leitor ainda esteja a pensar no problema apresentado por Gigerenzer (2005: 18) e não tenha conseguido calcular quantas das 10 mulheres com resultado positivo na mamografia têm, de facto, cancro da mama, digo-lhe que o resultado é uma (1) mulher!

Isto significa que se ao fim de ler o primeiro excerto de texto ficou com a sensação de que a probabilidade seria de $90 \%$, pode agora verificar que a probabilidade de uma mulher com resultado positivo na mamografia ter, efectivamente, cancro de mama é apenas de $10 \%$. Parece indiscutível que a forma como nos expressamos vai influenciar a forma como os outros compreendem o mundo; se não o fizermos bem podemos estar a induzir os outros em erro! 
10. A título de exemplo, referimos aquele que é provavelmente o pior acidente industrial da história da humanidade. O desastre aconteceu na cidade indiana de Bhopal, onde ocorreu um vazamento de várias toneladas de gases tóxicos. Neste acidente morreram de imediato cerca de 3000 pessoas e mais de 500 mil ficaram feridas. A causa imediata da descarga deveu-se ao influxo de água num tanque de armazenamento de isocianeto de metila, mas as condições latentes que permitiram a ocorrência deste evento são muitíssimo mais extensas (REASON 1990). É importante não esquecer que os acidentes decorrem normalmente da articulação de vários factores (AREOSA 2009; 2012b; 2012c), ou seja, têm a montante múltiplas causas e circunstâncias (AREOSA e DWYER 2010), são heterodeterminados.

Paralelamente, o desastre de Bhopal permitiu-nos também romper com algumas «certezas» do passado: «The disaster raised three distinct questions about the project of "big development", which had been hitherto unquestioned for five decades. It drew attention to the asymmetric inequities built into the very structure of the project. Next, it questioned the promises of the hubris underlying the idea of development. Last, but by no means the least, it raised doubts about the compatibility of "big development" with true democracy» (RAJAN 2002: 376).

11. O exemplo seguinte ilustra exatamente esta situação: «Another example of a change in the master coupling paradigm has been the move from balloons to aeroplanes in air transportation. For nearly half of century between 1875 and 1925, commercial public air transportation was successfully made by airship. The airship era totally collapsed in a short period after the Hindenburg accident in New York in 1936, and was immediately replaced by the emerging aeroplane industry. Again, this change full preserved the main function of the system (transporting passengers by air)» (AMALBERTI 2006: 266).

12. De acordo com uma pesquisa realizada em Portugal sobre os «novos riscos», $75 \%$ dos inquiridos consideraram muito grave a eventualidade de ocorrer um acidente nuclear e $57 \%$ afirmaram estar muito preocupados com os efeitos sobre Portugal se ocorrer um acidente numa central nuclear num país próximo (DELICADO e GONÇALVES 2007: 692).

13. Os críticos de Ulrich Beck defendem que o sucesso do conceito de sociedade de risco deve-se mais a circunstâncias históricas (por exemplo, Luhmann vê este conceito como uma moda) do que propriamente a uma verdadeira teoria social consistente, isto é, defendem que a teoria de Beck circula entre a verdade e a profecia. É-lhe ainda apontada falta de precisão nas propostas políticas para lidar com os seus diagnósticos de riscos globais. Beck foi também apelidado como o teórico da catástrofe ou apocalíptico. É verdade que algumas frases de Beck são susceptíveis de causar algum alarmismo social, nomeadamente quando ele afirma que as centrais nucleares podem destruir ou contaminar todo um milénio. $O$ autor preconiza ainda que este tipo de riscos é socialmente desvalorizado e a utilização da noção (probabilística) do risco é mal comparada com, por exemplo, o acto de fumar, onde este último é considerado estatisticamente mais arriscado (BECK et al., 2000: 17). Nesta situação é visível que Beck está mais preocupado com as eventuais consequências dos acidentes em centrais nucleares (riscos sociais) do que com as elevadas probabilidades de danos à saúde do acto de fumar (riscos individuais).

14. A modernização reflexiva significa uma auto-destruição criativa da sociedade industrial. 0 termo reflexividade na perspectiva de Beck não significa essencialmente reflexão, significa, sobretudo, autoconfrontação entre os efeitos da sociedade de risco e da sociedade industrial, visto que esta última mostra-se incapaz de monitorizar e resolver determinadas situações incertas (BECK et al., 2000).

15. Na noite de 6 de Março de 1987 um navio de grande porte virou-se poucos segundos depois de ter abandonado o porto de Zeebrugge (Bélgica). O acidente provocou perto de 200 vítimas mortais. A principal causa apontada para explicar este acidente foi: erro humano! A embarcação que transportava automóveis para Inglaterra iniciou a sua marcha («para o desastre») com as portas de acesso ao convés abertas (zona de passagem dos carros para o interior do barco). Foi precisamente por aqui que acabou por entrar uma enorme quantidade de água, a qual provocou o desequilíbrio do ferry boat. Consta-se que havia uma enorme pressão sobre a tripulação para o 
cumprimento dos horários (e esta situação parece ter contribuído para potenciar a ocorrência de vários erros). Acreditamos que cada trabalhador tenha tentado fazer o seu melhor para optimizar a relação custo/benefício (para a empresa), num mundo em que as organizações são, cada vez mais, impelidas para serem competitivas. O problema é que este tipo de competição, por vezes, gera erros e acidentes (RASMUSSEN 1997). Todavia, é pertinente lembrar que em organizações complexas de alto risco é difícil alguém ter uma visão conjunta tão completa que consiga evitar sempre (sublinhamos a palavra sempre) este tipo de situações (AREOSA 2012b). É ainda importante lembrar que a segurança pode tornar-se num objectivo conflituante com outros objectivos da organização (nem sempre os múltiplos objectivos das organizações surgem em perfeita sintonia, aliás, muitas vezes não estão em sintonia). Porém, é quase sempre tão fácil encontrar algum vilão que cometeu um qualquer erro considerado inaceitável. Mas, tal como refere Perrow (1999), seria melhor que parássemos de culpar inocentes, pois o erro parece não estar tanto nas pessoas, mas antes na ultra-complexidade de alguns sistemas. Para além disso, é através do trabalho vivo (aquele que é acrescentado às prescrições formais) que se resolvem inúmeros problemas; na verdade, é isto que torna as organizações eficazes (DEJOURS 2013; AREOSA 2013).

16. Nos sistemas complexos e fortemente interligados uma das formas para tentar garantir a segurança é feita através da criação de mecanismos redundantes. A redundância organizacional (sistemas paralelos) é gerada mediante a duplicação sistémica para a mesma função (em caso de falha da primeira unidade actua a segunda). Deste modo, a redundância pode ser vista como um «mecanismo» protector perante a ocorrência de falhas. Porém, segundo Sagan (1993: 251), temos algumas evidências históricas que demonstram a inadequação de tentar assegurar a fiabilidade e a segurança das organizações a partir da junção de mais e mais partes redundantes nos sistemas.

\section{RESUMOS}

Os riscos sociais e tecnológicos podem ser compreendidos como uma espécie de antecâmara para a ocorrência de acidentes ou de outros eventos indesejados. 0 debate sobre as múltiplas formas e abordagens ao risco parece que se tornou central nos dias de hoje, apesar de o risco sempre ter acompanhado toda a história da humanidade. Todavia, não sabemos se o mundo é actualmente mais arriscado do que foi no passado, mas sabemos, por exemplo, que os cidadãos ocidentais têm vindo a aumentar a sua esperança média de vida, que a mortalidade infantil baixou drasticamente e que somos hoje mais saudáveis do que no passado, fruto, por exemplo, do desenvolvimento tecnológico. Apesar de todos os benefícios que a tecnologia nos proporcionou ela também é geradora de riscos graves e assustadores com os quais os nossos antepassados não tiveram de conviver, particularmente centrais nucleares, transportes aéreos (aviação), plataformas petrolíferas, engenharia genética e por aí adiante. É devido a toda esta ambivalência que não conseguimos responder satisfatoriamente se vivemos hoje num mundo mais arriscado ou mais seguro. Em resumo, este trabalho pretende discutir a ambivalência da tecnologia a partir da noção de risco, nomeadamente os seus aspectos positivos e negativos.

The social and technological risks can be understood as a kind of of antechamber to the occurrence accidents or other unwanted events. The debate about the multiple forms and risk approaches seems to have become crucial nowadays, although the risk has always been present throughout history of mankind. However we do not know if the world is now more risky than in 
the past, but we know for example, that western citizens have increased their average life expectancy, infant mortality dropped dramatically and we are now healthier than in the past, due for example to technological development. Despite all the benefits that technology has given us it also generates serious risks and scary with which our ancestors did not have to live with particularly nuclear plants, air transport, oil platforms, genetic engineering and so on. It's due to all this ambivalence that we cannot say exactly whether we now live in a riskier or safer world. In summary, this paper discusses the ambivalence of the technology from the risk concept, including its positive and negative aspects.

\section{ÍNDICE}

Keywords: risk, technology, accidents, uncertainty

Palavras-chave: risco, tecnologia, acidentes, incerteza

\section{AUTOR}

\section{JOÃO AREOSA}

joao.s.areosa@gmail.com

Docente no Instituto Superior de Educação e Ciências (ISEC) e no Instituto Superior de Línguas e Administração (ISLA) e investigador integrado no Centro de Investigação em Ciências Sociais (CICS) da Universidade Nova de Lisboa.

É Doutor e Mestre em sociologia do trabalho, do emprego e das organizações, pelo Instituto Universitário de Lisboa (ISCTE-IUL); licenciado em sociologia, é pós-graduado em Segurança, Higiene e Saúde no Trabalho. Docente no Instituto Superior de Línguas e Administração (ISLA) e no Instituto Superior de Educação e Ciências (ISEC), é investigador integrado no Centro Interdisciplinar em Ciências Sociais (CICS) da Universidade Nova de Lisboa, membro da estrutura organizativa da Rede de Investigação sobre Condições de Trabalho (RICOT) e do conselho de edição do International Journal on Working Conditions. Autor de dezenas de artigos científicos relacionados com as áreas do risco e dos acidentes e dos livros seguintes: $O$ lado escuro dos acidentes de trabalho: um estudo de caso no setor ferroviário (Famalicão, Húmus, 2012); Impacto social dos acidentes de trabalho (em parceria com Hernani Veloso Neto e Pedro Azeres: Vila do Conde, Civeri Publishing, 2012); Proceedings CICOT 2013. Working conditions international congress (em parceria com Hernani Veloso Neto e Pedro Azeres: Vila do Conde, Civeri Publishing, 2013); Riscos psicossociais no trabalho (em parceria com Hernani Veloso Neto e Pedro Azeres: Vila do Conde, Civeri Publishing, 2014). 